\title{
JM
}

Volume 5 No. 1 (Juli 2017)

(C) The Author(s)

\section{GAMBARAN PENGETAHUAN IBU HAMIL TENTANG KELAS IBU HAMIL DI WILAYAH KERJA PUSKESMAS NUSA INDAH KOTA BENGKULU \\ TAHUN 2016}

\section{DESCRIPTION OF MATERNAL MOTHER 'S KNOWLEDGE TOWARD MATERNAL CLASS IN THE WORKING AREA OF NUSA INDAH PUBLIC HEALTH CENTER BENGKULU 2016}

\author{
INDRA ISWARI \\ AKADEMI KEBIDANAN DEHASEN \\ Email : Indraiswari764@yahoo.co.id. Hp : 08127313872
}

\begin{abstract}
ABSTRAK
Program kelas ibu hamil adalah salah satu bentuk pendidikan prenatal yang dapat meningkatkan pengetahuan ibu hamil, terjadi perubahan perilaku positif sehingga ibu memeriksakan kehamilan dan melahirkan ke tenaga kesehatan dengan demikian akan meningkatkan persalinan ke tenaga kesehatan dan menurunkan angka kematian ibu dan anak. Penelitian ini bertujuan untuk diketahuinya gambaran pengetahuan ibu hamil tentang kelas ibu hamil di wilayah kerja puskesmas Nusa Indah kota Bengkulu tahun 2016. Penelitian ini merupakan penelitian deskriptif, populasi sebanyak 509 ibu hamil dan sampel sebanyak 84 responden dengan Teknik Accidental Sampling yang dilaksanakan di wilayah kerja puskesmas Nusa Indah kota Bengkulu tahun 2016. Hasil penelitian menunjukkan dari 84 responden terdapat (59,5\%) memiliki pengetahuan kurang, dan $(27,4 \%)$ memiliki pengetahuan cukup, sedangkan yang berpengetahuan baik yaitu $(13,1 \%)$. Diharapkan kepada pihak puskesmas untuk lebih meningkatkan mutu pelayanan dengan penyuluhan kepada ibu tentang kelas ibu hamil sehingga ibu mengetahui pentingnya kelas ibu hamil bagi ibu hamil.
\end{abstract}

Kata kunci : pengetahuan, ibu hamil, kelas ibu hamil

\begin{abstract}
Class program for pregnant women was a form of prenatal education to increase knowledge of pregnant women, positive behavioral changes so that mothers during their pregnancy and give birth to a health worker there by enhancing delivery to healthcare and reduce maternal mortality and Children. To describe the description of understanding of maternal mother toward maternal class in the working area of Nusa Indah Public Health Center Bengkulu 2016. This research was a descriptive study, a population of 509 pregnant women and a sample of 84 respondents with accidental sampling technique was implemented in Puskesmas Nusa Indah Kota Bengkulu 2016. Results showed of 84 respondents there (59.5\%) had less knowledge, and (27.4\%) had sufficient knowledge, while the good knowledge reached the number (13.1\%). It was expected that the health center to further improve the service quality and information to mothers about the class of pregnant women so that mothers know the importance of pregnant women classes for pregnant women.
\end{abstract}

Keywords: knowledge, maternal, maternal class 


\section{PENDAHULUAN}

Menurut WHO tahun 2011 Angka Kematian Ibu (AKI) di negara-negara Asia Tenggara seperti Malaysia $(29 / 100.000$ kelahiran hidup), Thailand (48/100.000 KH), Vietnam (59/100.000 KH), serta Singapore $(3 / 100.000 \mathrm{KH})$. Dibandingkan dengan negara-negara maju, angkanya sangat jauh berbeda seperti Australia (7/100.000 KH) dan Jepang (5/100.000 KH) (WHO, 2011).

Sustainable Development Goals (SDGs) adalah sebuah kesepakatan pembangunan baru pengganti Mellenium Development Goalds (MDGs). Masa berlakunya 20152030 sebuah dokumen berisikan 17 goals dan 169 sasaran pembangunan. SDGs berisi seperangkat tujuan transformatif yang disepakati dan berlaku bagi seluruh bangsa tanpa terkecuali. Salah satu target yang ingin dicapai yaitu untuk pada goals 5 kesetaraan gender, menurunkan angka kematian ibu (Hoelman, 2015).

Hasil Survei Demografi dan Kesehatan Indonesia (SDKI) tahun 2012, Angka Kematian Ibu (AKI) yang berkaitan dengan kehamilan, persalinan, dan nifas sebesar 359 per 100.000 kelahiran hidup. Angka ini masih cukup jauh dari target yang harus dicapai pada tahun 2015 yaitu 102 per 100.000 kelahiran hidup.

Program kelas ibu hamil adalah salah satu bentuk pendidikan prenatal yang dapat meningkatkan pengetahuan ibu hamil, terjadi perubahan perilaku positif sehingga ibu memeriksakan kehamilan dan melahirkan ke tenaga kesehatan dengan demikian akan meningkatkan persalinan ke tenaga kesehatan dan menurunkan angka kematian ibu dan anak (Kemenkes RI, 2011).

Kelas ibu hamil ini diadakan karena makin banyaknya Angka Kematian Ibu (AKI). Seluruh rangkaian hasil proses pelaksanaan kegiatan kelas ibu hamil sebaiknya dibuatkan laporan. Isi laporan memuat tentang waktu pelaksanaan, jumlah peserta, proses pertemuan, masalah dan hasil capaian pelaksanaan, hasil evaluasi.
Pelaporan oleh bidan atau pelaksana pertemuan kelas Ibu hamil dilakukan setiap selesai pertemuan atau setiap angkatan pelaksanaan kelas Ibu hamil, kabupaten dan provinsi pelaporan disusun setiap 3 (tiga) bulan sekali dan laporan tahunan (Kemenkes RI, 2011).

Berdasarkan data Dinas Kesehatan Kota Bengkulu, tercatat di Kota Bengkulu pada tahun 2012 jumlah ibu hamil sebanyak 6.856 orang dan jumlah kematian ibu sebanyak 6 kasus, pada tahun 2013 jumlah ibu hamil sebanyak 7.251 dan jumlah kematian ibu sebanyak 9 kasus, tahun 2014 jumlah ibu hamil sebanyak 7.093 dan jumlah kematian ibu sebanyak 4 kasus. (Dinkes, 2015).

Berdasarkan data di Wilayah Kerja Puskesmas Nusa Indah Kota Bengkulu ibu hamil yaitu sebanyak 499 orang dan jumlah kematian ibu sebanyak 2 kasus, pada tahun 2013 jumlah ibu hamil sebanyak 505 orang dan tidak ada kematian ibu, pada tahun 2014 jumlah ibu hamil sebanyak 489 orang, tidak ada kematian ibu sedangkan pada tahun 2015 jumlah ibu hamil sebanyak 509 orang dan tidak ada kematian ibu. Sedangkan jumlah kelas ibu hamil di Wilayah Kerja Puskesmas Nusa Indah Kota Bengkulu yaitu sebanyak 12 kelas ibu hamil yang diadakan 4 kali dalam satu bulan dan jumlah ibu yang mengikuti kelas ibu hamil sebanyak 461 ibu hamil.

Berdasarkan survey awal yang dilakukan penulis pada tanggal 06-12 Januari 2016 di Puskesmas Nusa Indah Kota Bengkulu, dari 14 orang ibu hamil yang ditemui saat ditanyakan tentang kelas ibu hamil terdapat 9 orang ibu hamil yang mengikuti kelas ibu hamil dan 5 orang ibu hamil tidak mengikuti kelas ibu hamil. Ibu hamil yang tidak mengikuti kelas ibu hamil dikarenakan ibu kurang mengetahui tentang manfaat apa saja jika mengikuti kelas ibu hamil dan juga ibu sibuk bekerja sehingga kurang mengetahui apa itu kelas ibu hamil.

\section{METODE PENELITIAN}

Metode penelitian yang digunakan dalam 
penelitian ini adalah metode deskiriptif, yaitu suatu metode penelitian yang digunakan untuk gambaran pengetahuan ibu hamil tentang manfaat kelas ibu hamil di wilayah kerja puskesmas Nusa Indah kota Bengkulu tahun 2016.

\section{Populasi}

Populasi dalam penelitian ini adalah seluruh ibu hamil di Wilayah kerja Puskesmas Nusa Indah Kota Bengkulu Tahun 2014 yaitu sebanyak 509 orang

\section{Sampel}

Jumlah sampel yang diambil untuk penelitian ini adalah sebanyak 84 responden dengan teknik pengambilan sampel menggunakan Teknik Accidental Sampling.

\section{HASIL PENELITIAN}

Analisis data yang digunakan dalam penelitian ini adalah analisa univariat untuk melihat distribusi frekuensi masing-masing variabel penelitian, baik variabel independen (tingkat pengetahuan) maupun variabel dependen (Kelas ibu hamil).

Tabel 1 Distribusi responden berdasarkan pengetahuan Ibu tentang Kelas Ibu Hamil di Puskesmas Nusa Indah Kota Bengkulu Tahun 2016

\begin{tabular}{cccc}
\hline No & Pengetahuan & Frekuensi (f) & $\begin{array}{c}\text { Presentase } \\
(\%)\end{array}$ \\
\hline 1 & Kurang & 50 & $59,5 \%$ \\
\hline 2 & Cukup & 23 & $27,4 \%$ \\
\hline 3 & Baik & 11 & $14,3 \%$ \\
\hline & Jumlah & 84 & 100 \\
\hline
\end{tabular}

Dari tabel 1 di atas di tunjukkan bahwa lebih dari sebagian (59,5\%) ibu hamil mempunyai pengetahuan kurang tentang kelas ibu hamil, hampir sebagian responden $(27,4 \%)$ mempunyai pengetahuan cukup sedangkan sebagian kecil responden $(14,3 \%)$ mempunyai pengetahuan baik tentang kelas ibu hamil.

Hasil penelitian ini menunjukkan bahwa dari 84 orang responden terdapat 50 orang $(59,5 \%)$ atau lebih dari sebagian responden mempunyai pengetahuan kurang tentang kelas ibu hamil, 23 orang $(27,4 \%)$ atau hampir sebagian responden yang mempunyai pengetahuan cukup tentang kelas ibu hamil dan sebagian kecil dari responden 11 orang $(13,1 \%)$ yang mempunyai pengetahuan baik tentang kelas ibu hamil.

Berdasarkan hasil penelitian dapat dijelaskan bahwa masih banyak ibu yang mempunyai pengetahuan kurang tentang kelas ibu hamil,dan masih sedikit ibu yang mempunyai pengetahuan baik mengenai kelas ibu hamil. Keadaan ini sangat disayangkan karena dengan mengikuti kelas ibu hamil, mereka akan menjadi lebih tau atau pengetahuannya bertambah mengenai kehamilan, perubahan tubuh dan keluhan selama kehamilan, perawatan kehamilan, persalinan, perawatan nifas, KB paska persalinan, perwatan bayi baru lahir, mitosmitos/ kepercayaan/ adat istiadat yang beredar di masyarakat, penyakit menular hingga akte kelahiran, karena materi yang diberikan berasal dari buku KIA yang berisi mengenai perawatan kehamilan, nutrisi ibu hamil, tanda-tanda bahaya kehamilan, persiapan persalinan, tanda-tanda persalinan, perawatan ibu nifas, tanda bahaya nifas dan kesehatan anak.

Hal ini sesuai dengan teori Notoatmodjo (2010) semakin tinggi pengetahuan seseorang tentang suatu hal, maka akan timbul pemikiran tentang segi positif dan negatif mengenai hal tersebut, pengetahuan ini berpengaruh terhadap sikap-sikap seseorang sesuai dengan pemikirannya, kalau positif akan menimbulkan sikap positif demikian pula sebaliknya. Pengetahuan atau kognitif merupakan dominan yang sangat penting untuk terbentuknya tindakan seseorang (overt behavior).

\section{PEMBAHASAN}

Pengetahuan yang kurang dapat di pengaruhi oleh beberapa faktor yaitu pendidikan, pekerjaan, usia, paritas, informasi 
dan umur kehamilan. seperti hasil penelitian ini untuk pengetahuan rendah tentang kelas ibu hamil yang dimiliki responden sebagian besar terdapat pada tingkat pendidikan dasar. hal ini terjadi dikarenakan tingkat pendidikan seseorang akan berpengaruh terhadap kemudahan penyerapan informasi serta akan lebih mudah menerima informasi yang didapatkan. didukung dengan teori dari Nursalam (2008), yang menyatakan pada umumnya semakin tinggi tingkat pendidikan seseorang semakin mudah menerima informasi dengan demikian untuk tingkat pendidikan yang lebih tinggi akan menyebabkan pengetahuan seseorang lebih baik jika dibandingkan dengan seseorang yang berpendidikan rendah sehubungan dengan proses penerimaan informasi.

Dilihat dari pekerjaan untuk pengetahuan yang rendah dimiliki responden sebagian besar pada responden yang bekerja. Penyebab secara umum untuk kondisi pengetahuan responden yang tidak bekerja lebih baik dari pengetahuan responden yang bekerja tentang kelas ibu hamil salah satunya lingkungan. Dengan lingkungan yang memungkinkan terjadinya pertukaran pengetahuan antar manusia. Dimana responden yang tidak bekerja akan secara mudah mengakses informasi dari lingkungan, teman dan lainnya. Hal ini sesuai dengan teori dari Hendra (2008), yang mengatakan dalam lingkungan seseorang akan memperoleh pangalaman yang akan berpengaruh terhadap cara pikir seseorang. Semakin banyak akses informasi yang dimiliki akan memberi efek semakin luas pengetahuan seseorang dan berdampak pada pengetahuan yang baik.

Jika dilihat dari usia responden yang berpengetahuan rendah tentang kelas ibu hamil pada umumnya responden yang berusia $<20$ tahun dikarenakan pengalamannya yang kurang jika dibandingkan dengan yang sudah tua, semakin tua seseorang semakin banyak pengalamannya dan semakin bertambah pula pengetahuannya. Didukung dengan keterangan dari Hendra (2008), menyatakan meskipun semakin tua seseorang maka proses-proses perkembangan mental bertambah baik.

Dilihat dari paritas, berdasarkan hasil penelitian menunjukkan bahwa pengetahuan responden primipara lebih rendah dibandingkan dengan responden multipara. Paritas disini memiliki pengaruh yang signifikan dimana semakin banyak anak yang dilahirkan semakin banyak pengetahuan yang dimiliki tentang kehamilan yang akan berdampak pada pengetahuan yang baik. Dan hal tersebut didukung oleh teori yang dari Nursalam (2011), yang menyatakan pengalaman merupakan pendekatan yang penting untuk membentuk suatu pengetahuan. Dimana semakin banyak pengalaman seseorang maka penerimaan akan semakin mudah dan berdampak pengetahuan yang baik.

Hal ini sesuai dengan hasil penelitian yang dilakukan oleh novita sari (2012) yaitu pengetahuan ibu hamil tentang kelas ibu hamil sangatlah rendah, itu terbukti dari hasil penelitian dari 81 responden hanya 8 responden yang mempunyai pengetahuan baik itu disebabkan oleh beberapa aspek seperti pendidikan, pekerjaan, usia, paritas, umur kehamilan dan juga tenaga kesehatan setempat.

Berdasarkan hasil penelitian dan beberapa teori yang telah dikemukakan dapat disimpulkan bahwa pengetahuan ibu mengenai kelas ibu hamil sangat penting dimiliki oleh ibu hamil, karena dengan mengetahui tentang kelas ibu hamil ibu dapat merubah perilaku ibu untuk mengikuti kelas ibu hamil dalam upaya peningkatan pengetahuan dan keterampilan ibu-ibu mengenai kehamilan, perawatan kehamilan, persalinan, perawatan nifas, perawatan bayi baru lahir, mitos, penyakit menular dan akte kelahiran. Karena dalam proses penyerapan pengetahuan dapat dipengaruhi oleh banyak faktor seperti pendidikan, pekerjaan, usia, pengalaman, kebudayaan dan informasi.

\section{KESIMPULAN}

Dari hasil penelitian tentang gambaran pengetahuan ibu hamil tentang kelas ibu 
hamil di wilayah kerja puskesmas Nusa Indah kota Bengkulu tahun 2016 diperoleh kesimpulan lebih dari sebagian $(59,5 \%)$ ibu hamil mempunyai pengetahuan kurang tentang kelas ibu hamil.

\section{SARAN}

1. Bagi Akademi Kebidanan Dehasen

Diharapkan agar pihak Akademi dapat menambah referensi dan materi kelas ibu hamil di dalam pembelajaran untuk mahasiswa kebidanan agar selalu berusaha untuk meningkatkan pengetahuan, kemampuan dan keterampilan dalam mengajak ibu hamil untuk mengikuti pelaksanaan kelas ibu hamil.

2. Bagi tenaga kesehatan (Puskesmas)

Puskesmas adalah salah satu pelayanaan kesehatan yang berbasis preventif, promotif, dan kuratif. Untuk meningkatkan kualitas pelayanan maternal, maka di perlukan bagi pihak puskesmas untuk melakukan sosialisasi kepada ibu hamil tentang kelas ibu hamil, menyelenggarakan pelaksanaan kelas ibu hamil agar ibu hamil dapat mengetahui lebih banyak tentang masalah dalam kehamilan dan menyelenggarakan pelaksanaan kelas balita agar ibu lebih mengerti tentang perawatan balita, karena program kelas ibu hamil dan kelas balita merupakan program wajib bagi puskesmas.

3. Bagi peneliti lain

Hasil penelitian ini diharapkan dapat menjadi referensi dan koreksi untuk penelitian selanjutnya dan dapat menambah pengetahuan dan wawasan bagi peneliti lain khususnya tentang kelas ibu hamil dalam upaya meningkatkan pengetahuan ibu hamil.

\section{DAFTAR PUSTAKA}

Arikunto, S(2010). Prosedur Penelitian Suatu Pendekatan Praktek. Jakarta: Rineka Cipta.

(2008). Prosedur Penelitian

Suatu Pendekatan Praktek. Jakarta: Rineka Cipta.

Azwar (2008). Sikap Manusia. Jogjakarta: Liberty

Dinkes Kota Bengkulu. (2015). Profil Kesehatan Kota Bengkulu Tahun 2014. Bengkulu: Dinas Kesehatan Kota

Dinkes Provinsi Bengkulu. (2014). Profil Kesehatan Propinsi Bengkulu Tahun 2013. Bengkulu: DinasKesehatan Propinsi

Hidayat, A,A,A. (2013). Ilmu Kesehatan Anak Untuk Pendidikan Kebidanan. Jakarta: Salemba Medika.

Kemenkes, RI(2011). Pedoman Kelas Ibu Hamil. Jakarta: Departemen Kesehatan Republik Indonesia.

Kemenkes, RI (2014). Profil kesehatan indonesia. Jakarta: Departemen Kesehatan Republik Indonesia.

Notoatmodjo, S (2012). Metodologi Penelitian Kesehatan. Jakarta: Rineka Cipta

(2010). Ilmu Kesehatan Masyarakat. Jakarta: Rineka Cipta

Nursalam. (2008). Konsep dan Penerapan Metode Penelitian Ilmu Keperawatan. Salemba Medika: Jakarta

Sunaryo. (2008). Psikologi Untuk Keperawatan, Jakarta: EGC 